\title{
Erratum to: The effect of long term aging on the structural and optical properties of nano metallo-tetraphenylporphine films
}

\author{
A. El-Denglawey ${ }^{1,2} \cdot$ M. M. Makhlouf ${ }^{1,3,4} \cdot$ M. Dongol $^{2} \cdot$ M. M. El-Nahass ${ }^{5}$
}

Published online: 10 June 2015

(c) Springer Science+Business Media New York 2015

\section{Erratum to: J Mater Sci: Mater Electron}

DOI 10.1007/s10854-015-3017-0

The Acknowledgement was inadvertently omitted from the original publication of this article. It is now included with this erratum:

Acknowledgments This work was supported by the vicePresidency of graduate studies and academic research (Taif University, KSA), Project ID: 1-435-3430 (2014). It is gratefully acknowledged.

The online version of the original article can be found under doi:10.1007/s10854-015-3017-0.

A. El-Denglawey

denglawey@1ycos.com

1 Physics Department, Faculty of Applied Medical Sciences, Taif University, Turabah 21995, KSA

2 Nano and Thin Film Laboratory, Physics Department, Faculty of Science, South Valley University, Qena 83523, Egypt

3 Physics Department, Damietta Cancer Institute, Damietta, Egypt

4 Physics Department, Faculty of Science at New Damietta, Damietta University, New Damietta 34517, Egypt

5 Physics Department, Faculty of Education, Ain Shams University, Roxy, Cairo 11757, Egypt 